\title{
High-Efficiency Corrugated Monocrystalline Silicon Solar Cells with Multi-Directional Flexing Capabilities
}

\author{
Nazek El-Atab ${ }^{1}$, Rana Shamsuddin ${ }^{2}$, Rabab Bahabry $^{3}$ and Muhammad M. Hussain ${ }^{1,4}$ \\ ${ }^{1}$ MMH Labs, Computer Electrical Mathematical Science and Engineering Division, King Abdullah \\ University of Science and Technology (KAUST), Thuwal 23955-6900, Saudi Arabia. \\ ${ }^{2}$ Department of Physics, King Abdulaziz University (KAU), Jeddah 21589-80200, Saudi Arabia. \\ ${ }^{3}$ Department of Physics, University of Jeddah, Al Faisaliah Campus, Jeddah 21589-80200, Saudi Arabia. \\ ${ }^{4}$ EECS, University of California, Berkeley, California, USA
}

\begin{abstract}
High efficiency, lightweight and low cost flexible solar cells have attracted a growing interest in the last decades due to their increased applications. Here, we show high-efficiency $(19 \%)$ and large scale $(5 \times 5$ inch wafer) monocrystalline silicon solar cells with multi-directional flexing capabilities. The flexing of rigid solar cells with interdigitated back contacts is achieved using a photolithography-less corrugation technique. Results show that linear patterns enable flexibility in one direction with a minimum bending radius of $5 \mathrm{~mm}$ while diamond patterns result in multi-directional flexibility with different minimum bending radii and robust electrical performance.
\end{abstract}

\section{INTRODUCTION}

Flexible solar cells technology has paved the way for many applications ranging from wearable electronics and robotics to unmanned aerial vehicles and space applications [1-4]. Till today, the dominant material for photovoltaics remains silicon (under its various crystalline forms) due to its abundance, low cost and good efficiency [5-6]. However, fabricating lightweight and flexible silicon solar cells comes with tradeoffs in terms of efficiency and robustness [6].

In this work, we transform high-efficiency rigid monocrystalline silicon solar cells with interdigitated back contacts (IBC) configuration into flexible solar cells with no degradation of the original electrical performance. The process is based on a photolithography-less corrugation technique where grooves with no silicon [7] and different patterns are created across the solar cell using a plasma etch process. Previously, we have demonstrated flexible solar cells using the corrugation technique with linear patterns which resulted in one directional flexing capability and loss of active area of $13.3 \%$ [8]. In this work, we reduce the area loss in the linear corrugated flexible solar cells to $5.6 \%$; in addition, we show that different patterns, such as diamond corrugation, enable the solar cells to be flexed in multi-directions. The effect of different corrugated patterns (linear and diamond patterns) on the electrical characteristics, flexing directionality and minimum bending radius of the resulting flexible solar cells are studied.

\section{EXPERIMENTAL METHODS}

The corrugation process - a photolithography-less process was applied on $5 \times 5 \mathrm{inch}^{2}$ commercial monocrystalline silicon solar cells with $240 \mu \mathrm{m}$ thickness and IBC. First, the solar cells are spin-coated with positive photoresist PR 9260 on both sides, followed by the application of Kapton tape of the top side of the sample. Next, the Kapton is patterned using a $\mathrm{CO}_{2}$ laser and the exposed photoresist is removed using oxygen plasma. Finally, the exposed silicon areas are etched in a deep reactive ion etching (DRIE) system using the Bosch process until the IBC are exposed. This results in $135-\mu \mathrm{m}$ wide grooves in the silicon. Finally, the remaining Kapton is lifted off using acetone. Fig. 1a shows an illustration of the corrugation process with the different directions of the bending axes (Fig. 1b).

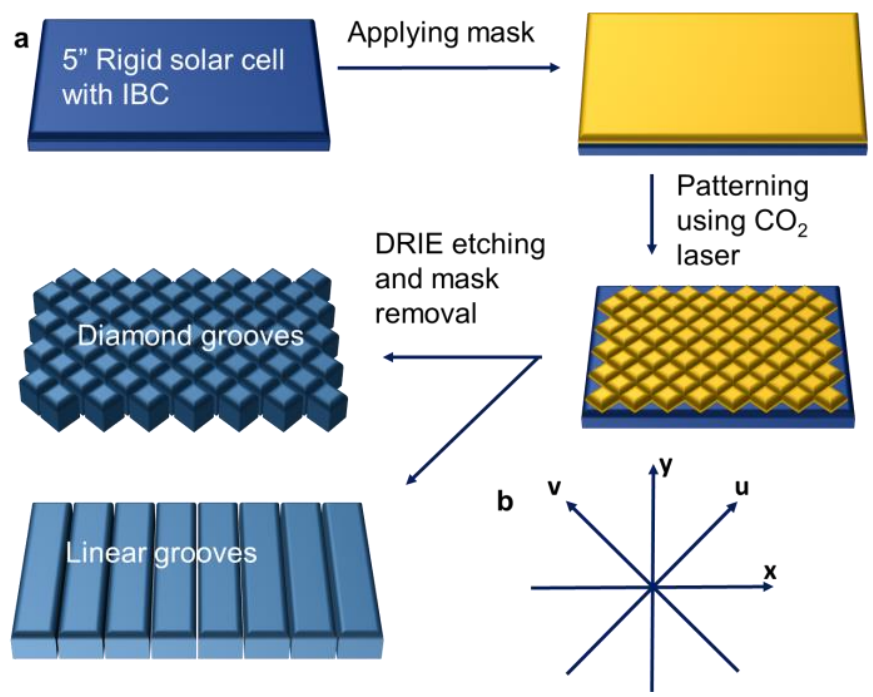

Fig. 1. (a) Illustration of the corrugation process of the solar cells. (b) Direction of bending axes. 


\section{RESULTS AND DISCUSSION}

\section{A. Area Loss in Corrugated Architectures}

The area loss in the corrugated silicon solar cells (linear and diamond) is calculated by considering a unit cell in each of the structures and measuring the reduced area due to the etching of silicon. The linear architecture results in an active area loss of $5.6 \%$ compared to the rigid one, while the diamond architecture results in $6.25 \%$ area loss. The measured weight of the rigid sample (12.by $2.5 \mathrm{~cm}^{2}$ ) is $2.44 \mathrm{~g}$, while $2.3 \mathrm{~g}$ for the linear corrugated sample and $2.28 \mathrm{~g}$ for the diamond corrugated sample which agrees well with the calculated area loss percentages. The weight loss of the flexible solar is beneficial for applications where the weight is a critical factor.

\section{B. Mechanical Flexibility}

The mechanical flexibility of the corrugated solar cells with linear and diamond patterns is studied by bending the solar cells and checking under an optical microscope if any cracks within the silicon are generated. The linear corrugated solar cells are found to provide flexibility in one direction (along the $\mathrm{y}$-axis as shown in Fig. $2 \mathrm{a}$ with a minimum bending radius of 5 $\mathrm{mm}$. The diamond cell provides flexibility in 4 directions with a minimum bending radius of $5 \mathrm{~mm}$ along the $\mathrm{u} / \mathrm{v}$ axes (Fig. $2 \mathrm{~b}$ ) and $2 \mathrm{~cm}$ along $\mathrm{x} / \mathrm{y}$ axes (Fig. $2 \mathrm{~d}$ ). Table I summarizes the measured bending radii of the two structures.

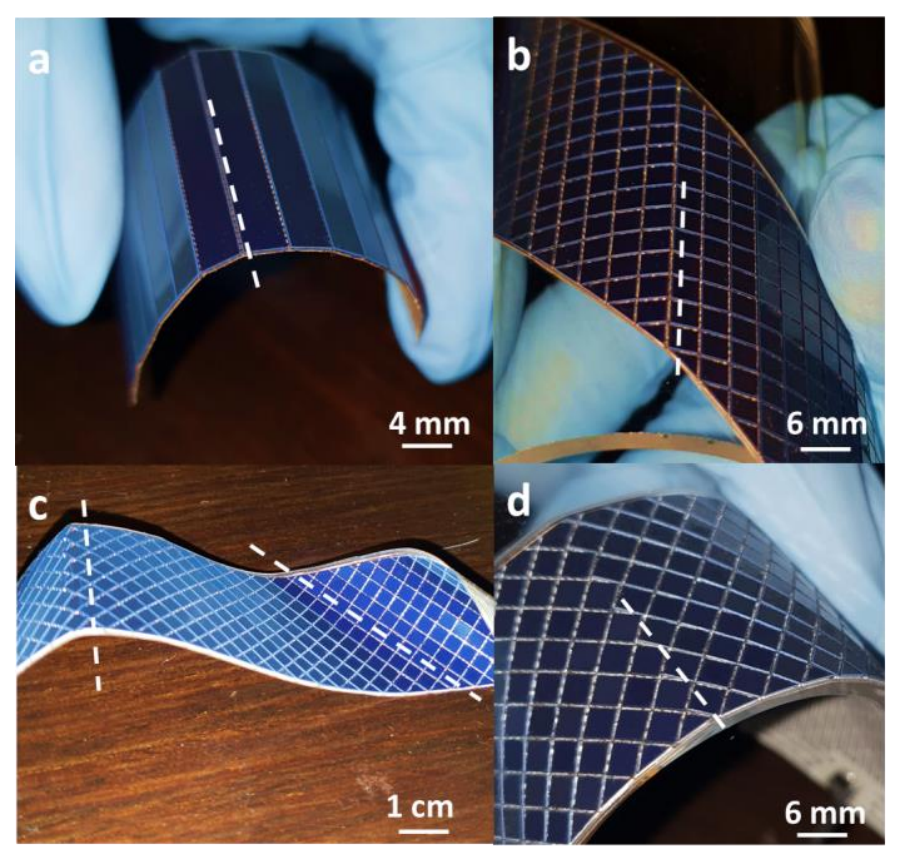

Fig. 2. (a) Corrugated solar cell with linear patterns along the yaxis. (b) Corrugated solar cell with diamond patterns bent along the $\mathrm{u} / \mathrm{v}$ axes. (c) Corrugated solar cell with diamond patterns bent along both $\mathrm{x} / \mathrm{y}$ and $\mathrm{u} / \mathrm{v}$ axes. (d) Corrugated solar cell with diamond patterns bent along the $\mathrm{x} / \mathrm{y}$ axes. The dashed lines in the figures show the direction of the different axes.
It is also worth to mention that the diamond patterned solar cells can be fixed in both $\mathrm{x} / \mathrm{y}$ and $\mathrm{u} / \mathrm{v}$ directions at the same time as shown in Fig. 2c.

\section{J-V Characteristics}

The J-V characteristics and power density of the rigid and corrugated samples (when flat) are measured and shown in Fig. $3 \mathrm{a}$ and Fig. 3b. The plot shows that the solar cells electrical performance is maintained after corrugation. However, the power output is reduced from $591.6 \mathrm{~mW}$ with the rigid solar cell with an area of 12.5 by $2.5 \mathrm{~cm}^{2}$ to $556 \mathrm{~mW}$ with the linear architecture and to $551 \mathrm{~mW}$ with the diamond architecture. This is due to the active silicon area loss after the corrugation process. The main characteristics of the solar cells are summarized in Table II (average taken for five characterized samples). In addition, the electrical performance of the solar cells is measured when mounted on curved substrates with bending radii of $4 \mathrm{~cm}$ and $5 \mathrm{~cm}$. The projection area of the bent solar cells is taken into consideration when calculating the current and power density. As shown in Fid. 3c, the solar cells show robust performance at different bending radii (Fig. 3c).

TABLE I

Minimum Bending RAdiUS OF FLEXIBLE SOLAR CELLS

\begin{tabular}{|l|c|c|}
\hline & Linear & Diamond \\
\hline X-direction & - & $2 \mathrm{~cm}$ \\
\hline Y-direction & $5 \mathrm{~mm}$ & $2 \mathrm{~cm}$ \\
\hline U/V direction & - & $5 \mathrm{~mm}$ \\
\hline
\end{tabular}

Finally, in terms of heat dissipation, the corrugated architecture of the solar cells resembles the finned architecture of heat sinks where the surface area to volume ratio is increased [9-10]. This will therefore help in increasing the heat dissipation by natural convection. Since silicon solar cells efficiency drops down by around $0.4 \%$ for every $1^{\circ} \mathrm{C}$ rise in temperature [11], the corrugated architecture of solar cells is

TABLE II

SUMMARY OF RIGID AND FLEXIBLE SOLAR CELLS CHARACTERISTICS

\begin{tabular}{|l|c|c|c|}
\hline & Rigid & Linear & Diamond \\
\hline Area loss & $0 \%$ & $5.6 \%$ & $6.25 \%$ \\
\hline$J_{s c}$ & $\begin{array}{c}39.12 \\
\mathrm{~mA} / \mathrm{cm}^{2}\end{array}$ & $\begin{array}{c}38.93 \\
\mathrm{~mA} / \mathrm{cm}^{2}\end{array}$ & $38.7 \mathrm{~mA} / \mathrm{cm}^{2}$ \\
\hline $\mathrm{V}_{\mathrm{oc}}$ & $0.645 \mathrm{~V}$ & $0.644 \mathrm{~V}$ & $0.641 \mathrm{~V}$ \\
\hline$\eta$ & $19.1 \%$ & $18.96 \%$ & $18.89 \%$ \\
\hline FF & $75.9 \%$ & $75.82 \%$ & $75.77 \%$ \\
\hline Specific weight & $780.8 \mathrm{~g} / \mathrm{m}^{2}$ & $736 \mathrm{~g} / \mathrm{m}^{2}$ & $729.6 \mathrm{~g} / \mathrm{m}^{2}$ \\
\hline
\end{tabular}


expected to reduce the heat effect on the solar cells when compared to the rigid structure.
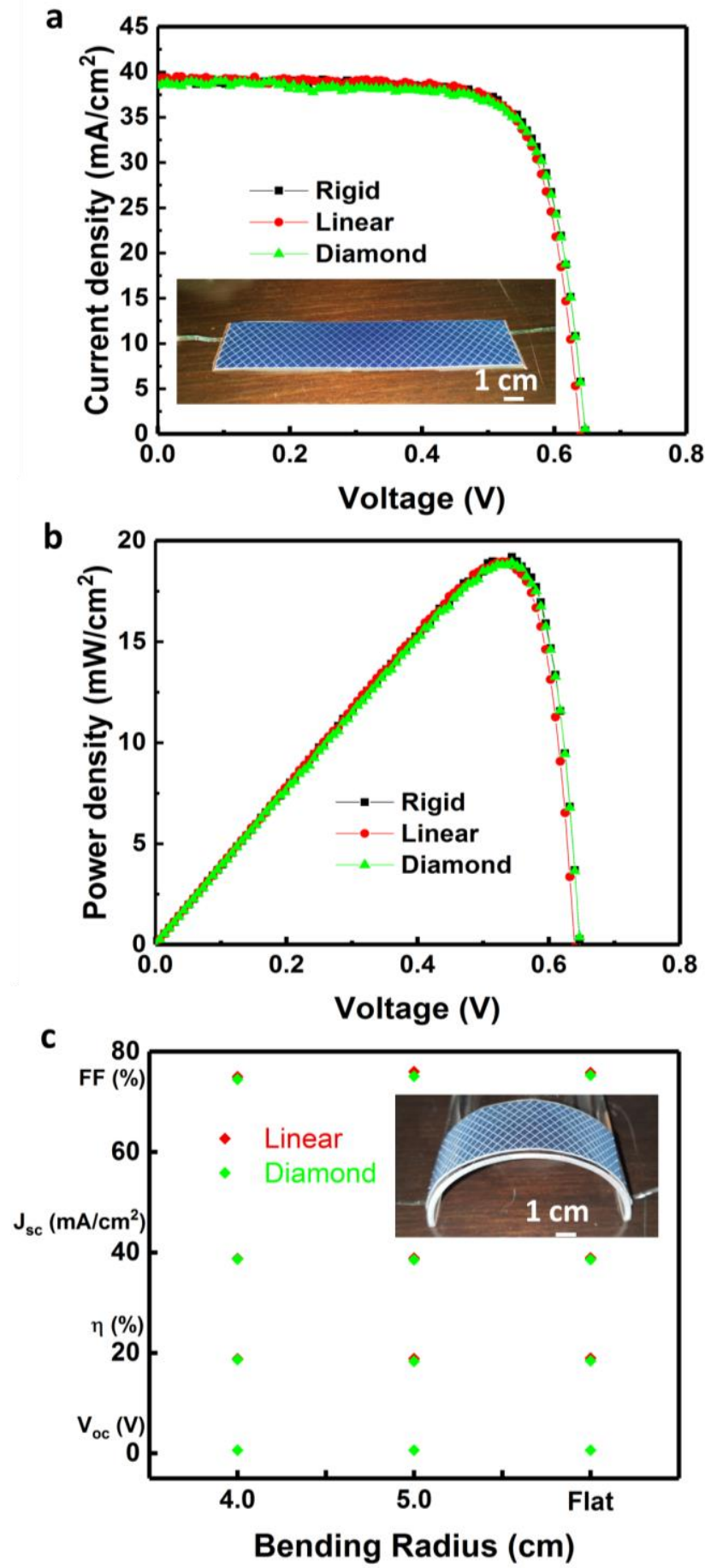

Fig. 3. (a) J-V characteristics of the rigid and corrugated solar cells. (b) Power density-voltage characteristics of the rigid and corrugated solar cells. (c) Electrical characteristics of the solar cells when bent with $4 \mathrm{~cm}$ and $5 \mathrm{~cm}$ bending radii.

\section{CONCLUSION}

Flexible monocrystalline silicon solar cells with high efficiency (19\%) and multi-directional flexing capabilities are demonstrated. The flexible solar cells are fabricated using a lithography-less corrugation process based on DRIE. Different corrugated patterns (linear and diamond) show different flexing directionalities. The results show a robust electrical performance of the flexible and bent solar cells with no degradation of the original electrical characteristics.

\section{REFERENCES}

[1] R. B. Bergmann, C. Berge, T. J. Rinke, J. Schmidt, and J. H. Werner, "Advances in monocrystalline Si thin film solar cells by layer transfer," Solar Energy Materials and Solar Cells, vol. 74, pp. 213-218, 10// 2002.

[2] A. J. Baca, K. J. Yu, J. Xiao, S. Wang, J. Yoon, J. H. Ryu, et al., "Compact monocrystalline silicon solar modules with high voltage outputs and mechanically flexible designs," Energy \& Environmental Science, vol. 3, pp. 208-211, 2010.

[3] C. H. Lee, D. R. Kim, and X. Zheng, "Transfer Printing Methods for Flexible Thin Film Solar Cells: Basic Concepts and Working Principles," ACS Nano, vol. 8, pp. 8746-8756, 2014/09/23 2014.

[4] D. J. Lipomi and Z. Bao, "Stretchable, elastic materials and devices for solar energy conversion," Energy \& Environmental Science, vol. 4, pp. 3314- 3328, 2011.

[5] A. Blakers, N. Zin, K. R. McIntosh, and K. Fong "High Efficiency Silicon Solar Cells, “ Energy Procedia, vol. 33, pp. 110, 2013.

[6] J. Yoon, Baca, A.J., Park, S.I., Elvikis, P., GEDDES III, J.B., Li, L., Kim, R.H., Xiao, J., Wang, S., Kim, T.H. and Motala, M.J., 2011. "Ultrathin silicon solar microcells for semitransparent, mechanically flexible and microconcentrator module designs" Nature Materials, vol. 7, pp. 907-915, 2008.

[7] R. R. Bahabry, A. T. Kutbee, S. M. Khan, A. C. Sepulveda, I. Wicaksono, M. Nour, et al., "Corrugation Architecture Enabled Ultraflexible Wafer-Scale High-Efficiency Monocrystalline Silicon Solar Cell," Advanced Energy Materials, vol. 8, pp. $1702221,2018$.

[8] R. R. Bahabry, A.C. Sepulveda, A.T. Kutbee, S.F. Shaikh, and M.M. Hussain, 2018, June. Corrugation Architecture Enabled Ultra-Flexible Mono-Crystalline Silicon Solar Cells via Plasma Etching and Laser Ablation. In 2018 IEEE 7th World Conference on Photovoltaic Energy Conversion (WCPEC)(A Joint Conference of 45th IEEE PVSC, 28th PVSEC \& 34th EU PVSEC) (pp. 0289-0292).

[9] L. Ventola, E. Chiavazzo, F. Calignano, D. Manfredi, and P. Asinari. "Heat transfer enhancement by finned heat sinks with micro-structured roughness," Journal of Physics: Conference Series, vol. 494, p. 012009, 2014.

[10] E. Radziemska. "The effect of temperature on the power drop in crystalline silicon solar cells," Renewable energy, vol. 28, pp.1$12,2003$.

[11] D.H. Kumar, H.E. Patel, V.R. Kumar, T. Sundararajan, T. Pradeep and S.K. Das. "Model for heat conduction in nanofluids," Physical Review Letters, vol. 93, p. 144301, 2004. 